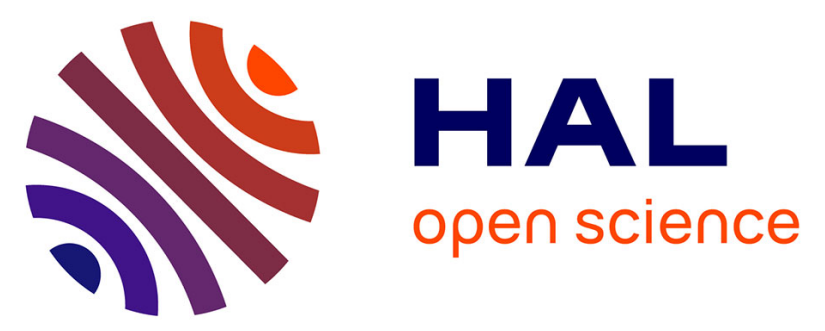

\title{
Operando X-ray Absorption Spectroscopy Investigation of Photocatalytic Hydrogen Evolution over Ultradispersed Pt/TiO 2 Catalysts
}

L. Piccolo, P. Afanasiev, Franck Morfin, Thomas Len, Caroline Dessal, J. L. Rousset, M. Aouine, Frédéric Bourgain, Antonio F Aguilar-Tapia, Olivier Proux, et al.

\section{To cite this version:}

L. Piccolo, P. Afanasiev, Franck Morfin, Thomas Len, Caroline Dessal, et al.. Operando X-ray Absorption Spectroscopy Investigation of Photocatalytic Hydrogen Evolution over Ultradispersed Pt/TiO 2 Catalysts. ACS Catalysis, 2020, 10 (21), pp.12696-12705. 10.1021/acscatal.0c03464 . hal-02994259

\section{HAL Id: hal-02994259 \\ https://hal.science/hal-02994259}

Submitted on 7 Nov 2020

HAL is a multi-disciplinary open access archive for the deposit and dissemination of scientific research documents, whether they are published or not. The documents may come from teaching and research institutions in France or abroad, or from public or private research centers.
L'archive ouverte pluridisciplinaire HAL, est destinée au dépôt et à la diffusion de documents scientifiques de niveau recherche, publiés ou non, émanant des établissements d'enseignement et de recherche français ou étrangers, des laboratoires publics ou privés. 


\title{
Operando X-ray Absorption Spectroscopy Investigation of Photocatalytic Hydrogen Evolution over Ultradispersed $\mathrm{Pt} / \mathrm{TiO}_{2}$ Catalysts
}

\author{
L. Piccolo, ${ }^{1,}{ }^{*}$ P. Afanasiev, ${ }^{1}$ F. Morfin, ${ }^{1}$ T. Len, ${ }^{1}$ C. Dessal, ${ }^{1}$ J.L. Rousset, ${ }^{1}$ M. Aouine, ${ }^{1}$ F. \\ Bourgain, ${ }^{1}$ A. Aguilar-Tapia, ${ }^{2}$ O. Proux, ${ }^{3}$ Y. Chen, ${ }^{4}$ L. Soler, ${ }^{4}$ J. Llorca ${ }^{4}$ \\ ${ }^{1}$ Univ Lyon, Université Claude Bernard Lyon 1, CNRS, IRCELYON, F-69626 Villeurbanne, France. \\ ${ }^{2}$ Univ Grenoble Alpes, CNRS, Institut Néel, F-38000 Grenoble, France. \\ ${ }^{3}$ Univ Grenoble Alpes, CNRS, OSUG, F-38041 Grenoble, France. \\ ${ }^{4}$ Institute of Energy Technologies, Department of Chemical Engineering and Barcelona Research \\ Center in Multiscale Science and Engineering, Universitat Politècnica de Catalunya, EEBE, Eduard \\ Maristany 16, 08019 Barcelona, Spain. \\ *laurent.piccolo@ircelyon.univ-lyon1.fr
}

\begin{abstract}
Photocatalytic hydrogen production from water or oxygenates is foreseen as a sustainable energy production route. In spite of recent performance achievements through Pt particle downsizing, the knowledge on the prototypical $\mathrm{Pt} / \mathrm{TiO}_{2}$ photocatalyst operation mechanism, in particular the electronic state and the stability of the Pt phase under reaction conditions, remains limited. We have investigated atomically dispersed $\mathrm{Pt} / \mathrm{TiO}_{2}$ catalysts by pre/post-reaction scanning transmission electron microscopy and operando X-ray absorption spectroscopy - mass spectrometry in gas-phase ethanol dehydrogenation conditions under ultraviolet-visible light irradiation. The catalysts were prepared by a simple impregnation method on two types of commercial titania. While the general effect of the reaction on initially fully oxidized $\left(\mathrm{Pt}^{\mathrm{IV}}\right)$ single-atom catalysts (SACs) is $\mathrm{Pt}$ reduction and aggregation, this combined phenomenon can be inhibited in two manners. First, when supported on high-surfacearea anatase, the Pt SAC retains an intermediate oxidation state, and its clustering is limited to Pt dimers and trimers. Second, with the same support, a mild reducing pretreatment generates, through the formation of Pt-Ti bonds, near-neutral and ultradispersed Pt species (from single atoms to nanometric clusters) with the highest stability and activity in photocatalytic hydrogen evolution.
\end{abstract}

\section{Keywords}

Photocatalytic hydrogen production; Single-atom catalysis; $\mathrm{Pt} / \mathrm{TiO}_{2}$; Operando spectroscopy; XAS 


\section{Introduction}

Currently, hydrogen is mostly produced from fossil sources through catalytic steam reforming of methane. ${ }^{1}$ Since the discovery of Fujishima and Honda in $1972,{ }^{2}$ photocatalytic water splitting is seen as a promising route toward the sustainable production of this valuable energy carrier from sunlight and water. ${ }^{3-6}$ However, the development of water splitting faces serious technological challenges, including the suppression of the backward (hydrogen oxidation) reaction. The use of "sacrificial agents" (hole scavengers) such as methanol and ethanol limits this issue. ${ }^{7-10}$ An interesting possibility is thus to directly convert organic pollutants or biomass-derived feedstocks into hydrogen through photocatalytic reforming or dehydrogenation. ${ }^{11-14} \mathrm{TiO}_{2}$, especially its anatase polymorph, is the most popular photocatalytic material owing to its efficiency, photochemical stability, and abundance. ${ }^{15}$ However, photogenerated electron-hole pairs readily recombine at the titania surface (in the absence of hole scavenger), and most importantly bare titania surfaces possess low ability to recombine hydrogen atoms, leading to poor photocatalytic efficiency. Among the many ways of modifying $\mathrm{TiO}_{2}$ that have been employed to promote the photocatalytic hydrogen evolution reaction (PHER), the addition of a transition metal cocatalyst in the form of nanoparticles supported on the titania is probably the most successful one. The most probable role of the cocatalyst is to trap photoelectrons and protons, and favor $\mathrm{H}-\mathrm{H}$ coupling. ${ }^{16,17,8,18,19}$

A large body of researches concerns the PHER performance, reaction mechanism and active sites for the highly efficient $\mathrm{Pt} / \mathrm{TiO}_{2}$ system. ${ }^{7,8,20-23}$ With the recent emergence of single-atom catalysis, ${ }^{24}$ which holds promise in terms of precious metal saving and tuning of catalytic efficiency, there have been several reports on $\mathrm{Pt} / \mathrm{TiO}_{2}$ single-atom catalysts (SACs), ${ }^{25-36}$ and on various SACs for photocatalytic applications including PHER. ${ }^{37-41}$ However, the conclusions on the possible advantage of single atoms and related oxidic species over metallic nanoparticles in PHER are controversial.

Xing et al. elaborated by co-precipitation a $0.2 \mathrm{wt} \% \mathrm{Pt} / \mathrm{TiO}_{2}$ (anatase, $484 \mathrm{~m}^{2} / \mathrm{g}$ ) SAC, that they found more active for PHER from liquid methanol-water mixture (used in most studies) under UV-Vis light irradiation than nanoparticulate counterparts. ${ }^{42}$ These findings are consistent with the previous results of the same authors, showing that acid-leached $\mathrm{Pt} / \mathrm{TiO}_{2}$ catalysts containing exclusively oxidic and atomically dispersed Pt species are equally active as their non-leached parent catalysts containing metallic Pt nanoparticles. ${ }^{43}$ The same group also reported that few-atom PtO clusters loaded on anatase $\mathrm{TiO}_{2}$ nanosheets are more active than larger PtO particles. ${ }^{44}$ The use of PtO (instead of Pt) clusters was stated to suppress the undesirable hydrogen oxidation reaction. ${ }^{45}$ Sui et al. found that single Pt atoms selectively deposited through a photochemical route onto the (101) facets of shapecontrolled anatase $\mathrm{TiO}_{2}$ nanoparticles $(0.3-0.9 \mathrm{wt} \% \mathrm{Pt})$ are more active under simulated sunlight than 
supported Pt nanoparticles. ${ }^{46}$ However, the latter were not supported on the same titania material as the SACs, and in the SACs the single atoms actually coexisted with Pt clusters. Recently, Chen et al. prepared $0.02 \mathrm{wt} \% \mathrm{Pt}$ SACs supported on defective $\mathrm{TiO}_{2}$ elaborated from sodium titanate nanotubes. ${ }^{47}$ The so-formed Pt-O-Ti ${ }^{3+}$ interface integrating surface oxygen vacancies would be at the origin of the measured high PHER activity under UV-Vis light, which was again found much superior to that of a nanoparticulate catalyst. Similarly, Hejazi et al. claimed a high PHER activity under UV light of Pt atomically dispersed on pre-reduced anatase $\mathrm{TiO}_{2}$ layers prepared by magnetron sputtering. ${ }^{48}$ However, the stability on stream of the metal dispersion and chemical state was not reported.

At variance from the above studies suggesting the highest PHER activity of atomically dispersed and/or oxidized Pt species, Jiang et al. concluded from the use of several Pt deposition methods on the same anatase titania, that the PHER activity scales with the fraction of metallic platinum. ${ }^{49} \mathrm{In}$ a recent work, we have compared a series of $\mathrm{Pt} / \mathrm{TiO}_{2}$ photocatalysts with variable titania type for PHER from ethanolwater mixtures under UV light, both under liquid-phase and gas-phase conditions. ${ }^{50}$ Our results suggest that, for a similar impregnation-reduction procedure, the PHER activity increases as the Pt cluster decreases to $1 \mathrm{~nm}$, consistently with DFT calculations ${ }^{51}$ showing that this Pt cluster size would optimize the photoreaction process (a cluster size effect, ascribed to size-dependent electronic structure, was also evidenced by Schweinberger et al. for PHER on Pt/CdS). ${ }^{52}$ Atomically dispersed Pt species elaborated by impregnation-calcination exhibited lower PHER activity than their pre-reduced cluster counterparts..$^{50}$ However, from post-reaction scanning transmission electron microscopy (STEM), we have shown that part of these species sinters under PHER conditions, consistently with the findings of Liu et $a .^{53}$ and Jeantelot et al. ${ }^{54}$ This inherent trend of oxide-supported ultradispersed metal species to aggregate under reducing conditions ${ }^{55}$ can be limited - in the example of PHER on Pt/TiO - by using an ultralow Pt loading, a high titania support surface area, and/or titania surface defect engineering. ${ }^{42,47,48}$

From this ensemble of results, while the positive effect of a high Pt dispersion in PHER seems established, the actual structure and oxidation state of titania-supported active Pt species remain unclear. Notably, none of the above works employed operando catalyst characterization, a still rare approach in photocatalysis. ${ }^{56-58}$ Nevertheless, highly dispersed metal/titania catalysts are sensitive to their (photo)chemical environment ${ }^{28,39,59}$ and the operando approach can provide direct measurements of the influence of the reaction environment on photocatalytic systems. In this work, in addition to systematic pre- and post-reaction STEM, we have used operando X-ray absorption spectroscopy (XAS) combined with online mass spectrometry to investigate the Pt cocatalyst state under conditions of PHER in a flowing vapor-phase ethanol-water mixture. Two titania supports and two types of thermochemical pretreatment have been employed to determine the respective 
influences of the support surface area and the initial metal dispersion/oxidation state on the nature and stability of titania-supported Pt species under photocatalytic operation.

\section{Experimental section}

\section{Materials}

Two commercial $\mathrm{TiO}_{2}$ materials were used in this study, Evonik Aeroxide P90 (purity $>99.5 \%$ ) and Tronox CristalACTiV PC500 (purity $>99 \%$ ). P90 is a mixture of $92 \%$ anatase and $8 \%$ rutile phases, with $114 \mathrm{~m}^{2} / \mathrm{g}$ BET surface area. ${ }^{50} \mathrm{PC} 500$ is a mixture of $85 \%$ anatase and $15 \%$ amorphous phases, with 352 $\mathrm{m}^{2} / \mathrm{g}$ BET surface area. ${ }^{60}$

$\mathrm{Pt} / \mathrm{TiO}_{2}$ catalysts were prepared by incipient wetness impregnation with $\mathrm{Pt}\left(\mathrm{NH}_{3}\right)_{4}\left(\mathrm{NO}_{3}\right)_{2}$ precursor (Sigma-Aldrich, $>50 \% \mathrm{Pt}$ basis) dissolved in water. The impregnate was then dried at $60^{\circ} \mathrm{C}$ for $4 \mathrm{~h}$ and calcined in synthetic air or reduced in $\mathrm{H}_{2}\left(30 \mathrm{~mL} / \mathrm{min}, 300{ }^{\circ} \mathrm{C}, 2^{\circ} \mathrm{C} / \mathrm{min}, 2 \mathrm{~h}\right)$. Pt loadings (target values 0.2 and 1.0 wt\%) were determined by inductively coupled plasma - optical emission spectroscopy (ICPOES, Horiba Jobin Yvon Activa). Prior to ICP analyses, the samples were pretreated in $\mathrm{H}_{2}$ flow at $450^{\circ} \mathrm{C}$ and dissolved in an acid mixture at $300{ }^{\circ} \mathrm{C}$. Only $0.2 \mathrm{wt} \%$ Pt samples are considered here, except in Supporting Information (SI) where $1 \mathrm{wt} \% \mathrm{Pt} / \mathrm{P} 90$ samples serve as references.

The three main samples investigated in this study are denoted Pt/P90-C, Pt/PC500-C, and Pt/PC500-R (actual Pt loadings $0.18 \mathrm{wt} \%, 0.23 \mathrm{wt} \%$, and $0.23 \mathrm{wt} \%$, respectively). The suffix $-\mathrm{C}$ or $-\mathrm{R}$ corresponds to a pre-calcined or a pre-reduced catalyst, respectively. The Pt loadings of additional Pt/P90-C and Pt/P90-R samples were 0.91 and 0.82 wt\%, respectively.

\section{Scanning transmission electron microscopy}

The samples were analyzed by annular-dark-field STEM (ADF-STEM) using a FEI Titan ETEM G2 machine equipped with a Cs image aberration corrector and operated at $300 \mathrm{keV}$. See SI for details. 
The local structure of Pt species was investigated by XAS in partial fluorescence yield mode on the FAME-UHD beam line of the European Synchrotron Radiation Facility. X-ray absorption spectra at the $L_{3}$ edge of Pt were recorded.

The sample, in the form of a thin self-supported pellet (16 mm diameter, ca. $250 \mathrm{mg}$ ), was inserted in a custom-made polyoxomethylene gas cell equipped with Kapton windows for X-rays and a quartz window for UV-Vis light (Figure 1). The cell can be operated in transmission mode, but this possibility was not used here. The UV-Vis light was delivered by an Asahi Spectra MAX-302 Xe lamp (output power $300 \mathrm{~W}$ ) used at full intensity and full spectrum range (ca. 340-600 nm). A 4-way valve allowed flowing helium (100 $\mathrm{mL} / \mathrm{min}$ ) either directly to the gas cell or through a saturator containing a mixture of ethanol $(10 \%)$ and distilled water $(18 \mathrm{M} \Omega . \mathrm{cm})$. The mixture was maintained at $0{ }^{\circ} \mathrm{C}$ with a Peltier refrigerator. The gas flow at the cell outlet was continuously analyzed by an Aspec portable quadrupole mass spectrometer (MS).

As in the laboratory reactor (see below), the catalyst mass and the irradiation conditions were kept constant, making the evaluation of PHER activities in $\mu \mathrm{mol} / \mathrm{min}$ relevant, without the need for further normalization.

A typical protocol consisted of the following successive conditions at room temperature (RT) and atmospheric pressure: Dark Air, Dark He, Light He, Light EtOH, and Dark EtOH. Air, He and EtOH refer to static air atmosphere, pure helium flow, and ethanol/water/helium gas flow (EtOH: $\mathrm{H}_{2} \mathrm{O}=1: 9$, molar basis), respectively. The same sample was used for the above series of experimental conditions. At the beginning of each step, several XAS spectra were recorded until stabilization, from which additional spectra were recorded for extended X-ray absorption fine structure (EXAFS) and high energy resolution fluorescence detected X-ray absorption near edge spectroscopy (HERFD-XANES). Typically, 3 EXAFS (40 min per spectrum) and 5-10 XANES (7 min per spectrum) stabilized spectra were recorded at each step for averaging.

See SI for details on the beamline apparatus, XAS recording, and EXAFS fitting procedure. 


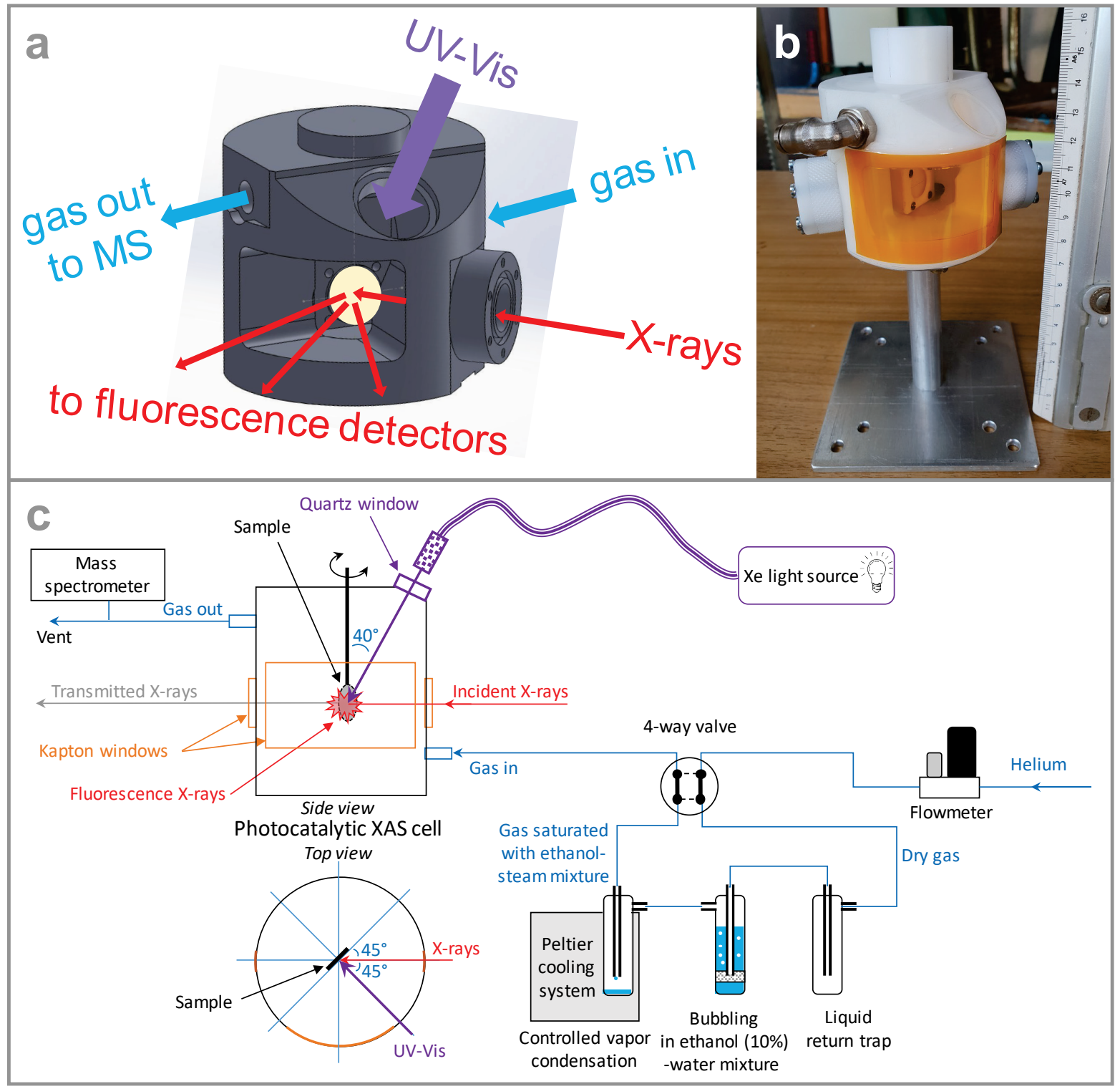

Figure 1. Operando XAS reactor setup: (a) scheme of the photocatalytic cell, (b) photograph of the cell, and (c) scheme of the overall reaction setup.

\section{Photocatalytic testing}

In addition to synchrotron measurements, laboratory photocatalytic tests were performed at RT and atmospheric pressure using a tubular glass photoreactor equipped with a $365 \pm 5 \mathrm{~nm}$ UV source and an online micro gas chromatograph. ${ }^{61,62}$ The gas stream consisted of an ethanol-water mixture (EtOH: $\mathrm{H}_{2} \mathrm{O}=1: 9$, molar basis) in an argon flow $(20 \mathrm{~mL} / \mathrm{min})$. The tested catalyst weight was $1.8 \pm 0.2$ mg. See Ref. ${ }^{50}$ for details. 


\section{Results}
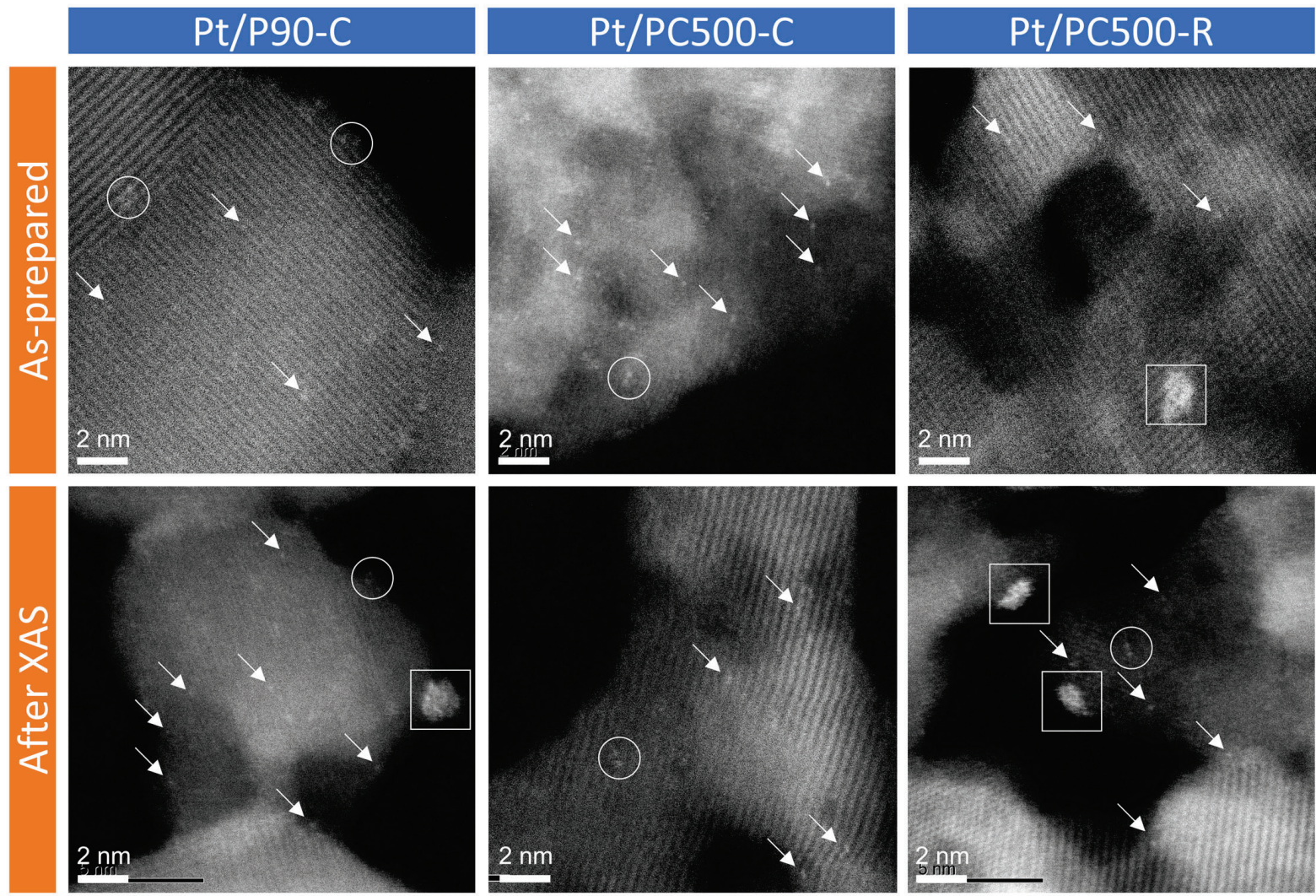

Figure 2. STEM-ADF images of as-prepared (top) and XAS-analyzed (bottom) $0.2 \mathrm{wt} \% \mathrm{Pt} / \mathrm{TiO}_{2}$ samples. $\mathrm{C}$ and $\mathrm{R}$ suffixes indicate pre-calcined and pre-reduced samples, respectively. Arrows, circles, and squares show single atoms, multimers, and clusters, respectively.

The top panel of Figure 2 shows representative STEM images of the three samples selected for XAS investigations (see Figures S1-S9 for additional images, together with size histograms and fractions of Pt species). The Pt/P90-C sample presents a large majority of single Pt atoms and few-Pt-atom clusters (multimers), though a fraction of ca. $0.8 \mathrm{~nm}$-sized Pt clusters was also detected (Figure S2). The $\mathrm{Pt} / \mathrm{PC500}-\mathrm{C}$ sample contains a large majority of single atoms as well as a fraction of few-atom clusters, without any detectable presence of larger clusters. Finally, the Pt/PC500-R sample exhibits, together with single atoms and multimers, a significant fraction of clusters with average size $1.3 \pm 0.3 \mathrm{~nm}$. In line with our previous work on Pt/P90 photocatalysts, ${ }^{50}$ while oxidizing treatments at moderate temperature (here, $300^{\circ} \mathrm{C}$ ) favor atomic dispersion, reducing treatments (here also $300^{\circ} \mathrm{C}$ ) favor the formation of Pt clusters to some extent on the PC500 support, in spite of its three times higher specific surface area with respect to P90. 


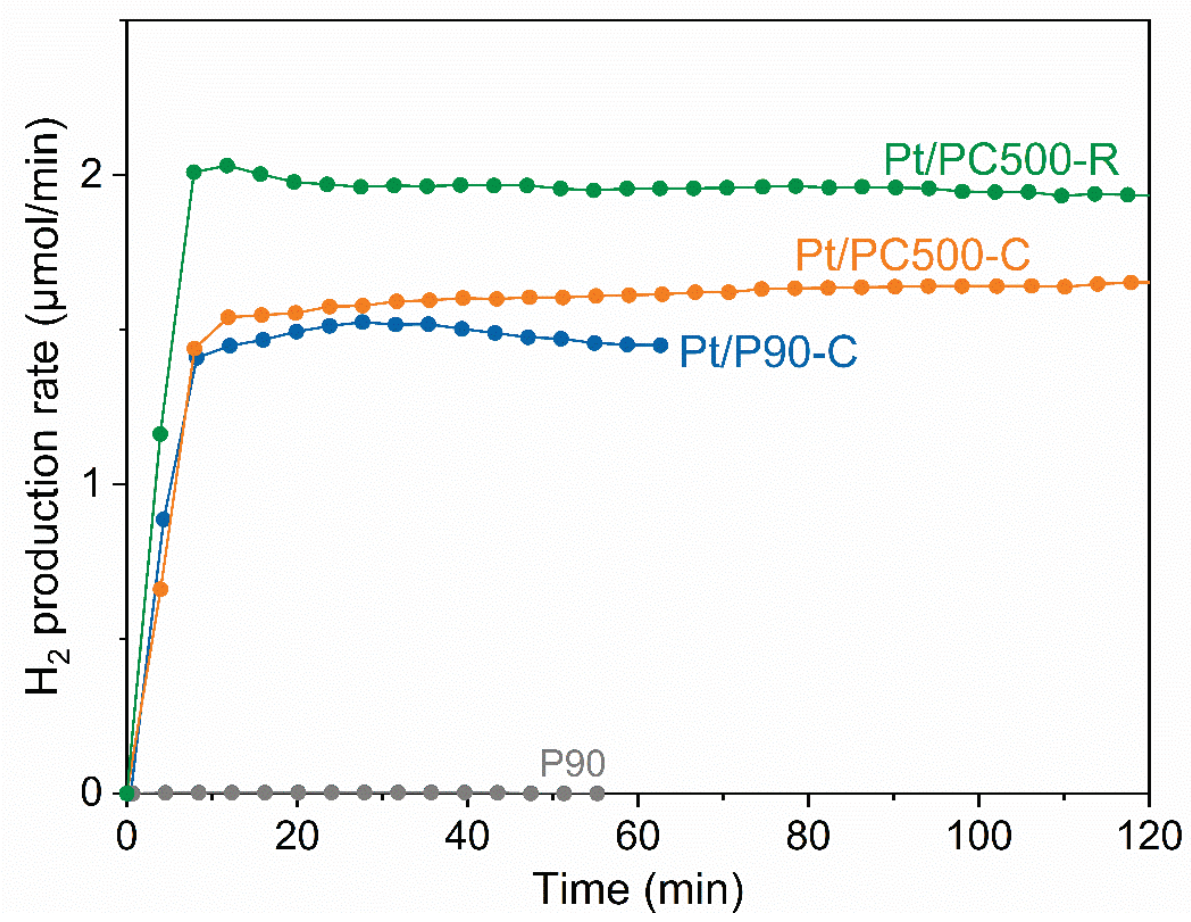

Figure 3. Comparison of $0.2 \mathrm{wt} \% \mathrm{Pt} / \mathrm{TiO}_{2}$ catalyst activities in PHER from ethanol/water/helium gas flow under UV irradiation at RT (laboratory reactor).

Figure 3 represents the rate of hydrogen evolution from gas-phase ethanol dehydrogenation over $\mathrm{Pt} / \mathrm{TiO}_{2}$ photocatalysts under UV irradiation. From the detection of only $\mathrm{H}_{2}$ and acetaldehyde (Figure S10) as products, which were formed in similar amounts, the primary reaction was ethanol dehydrogenation: $\mathrm{C}_{2} \mathrm{H}_{5} \mathrm{OH} \rightarrow \mathrm{C}_{2} \mathrm{H}_{4} \mathrm{O}+\mathrm{H}_{2}$.

Similar to what was obtained in our previous work for Pt/P90, ${ }^{50}$ the Pt/PC500 catalyst prepared by impregnation-reduction is (slightly) more active than the one prepared by impregnation-calcination. The $\mathrm{H}_{2}$ evolution rate over Pt/PC500-R after $1 \mathrm{~h}$ on stream is $2.0 \mu \mathrm{mol} / \mathrm{min}\left(0.14 \mathrm{~mol} \mathrm{~h}^{-1} \mathrm{~g}_{\text {cat }}{ }^{-1}\right.$, turnover frequency per $\mathrm{Pt}$ atom $0.37 \mathrm{~s}^{-1}$, photonic yield 5.6\%, apparent quantum yield $11 \%$ ). The $\mathrm{H}_{2}$ production rates of Figure 3 are consistent with literature data for $\mathrm{Pt} / \mathrm{TiO}_{2}$ catalysts among the most efficient. ${ }^{50}$ Nevertheless, though some authors claim very high PHER performances, we believe that such comparisons are delicate since the employed experimental conditions (gas vs liquid phase, nature and concentration of the alcohol, presence of mass-transfer and/or photon-transfer limitations, irradiation power, spectral range, etc.) can deeply influence the measured photocatalytic activity.

The activity difference between pre-calcined and pre-reduced samples is lower for PC500 than previously measured for $\mathrm{P} 90 .{ }^{50}$ Hence, already at this stage, it can be inferred that the high surface 
area of PC500, which permits to generate not only Pt clusters but also a large fraction of single Pt atoms through the reducing treatment, makes the PC500 samples less sensitive to the type of preparation treatment, and more structurally stable than the P90 samples. Besides, as previously pointed out, ${ }^{50}$ the titania phase and surface area have lower impacts than the Pt dispersion on the photocatalytic performances under our conditions.

In order to gain deeper insight into the reasons that account for the observed differences in the PHER efficiency of the samples containing ultradispersed Pt species on $\mathrm{TiO}_{2} \mathrm{P90}$ and $\mathrm{PC500}$, we performed a series of operando XAS measurements using an original custom-made cell (Figure 1). The evolution of hydrogen was simultaneously detected by MS (Figure S11). With respect to laboratory photocatalytic tests (Figure 3), the same activity order is observed between the catalysts: Pt/P90-C $<$ Pt/PC500-C < Pt/PC500-R. The initial transient reaction kinetics (especially the initial activity bump for Pt/PC500-C) seen in Figure S11 is not observed in Figure 3, likely owing to the differences in experimental conditions between the XAS cell and the laboratory photoreactor. However, the overall gradual deactivation of $\mathrm{Pt} / 90-\mathrm{C}$ and the gradual activation of Pt/PC500-C are reproduced in XAS-MS experiments.

The left panel of Figure 4 allows comparing HERFD-XANES spectra representative of the $\mathrm{Pt} / \mathrm{TiO}_{2}$ photocatalysts in initial conditions (static air, no light) and under PHER conditions (ethanol/water/helium gas flow, UV-Vis irradiation). Additionally, Figure S12 displays close views of the XANES white line (WL) in the whole range of conditions, and Figure S13 allows a direct comparison between the catalysts as well as with reference samples: $\mathrm{Pt}$ and $\mathrm{PtO}_{2}$ solids, pre-calcined and prereduced $1 \mathrm{wt} \% \mathrm{Pt} / \mathrm{TiO}_{2}$-P90 samples.

The XANES WL intensity typically reflects the metal oxidation state, though this simple interpretation can be complicated by the existence of particle size and shape effects. ${ }^{63,64}$ The WL intensity for the samples in Dark Air conditions decreases in the following order (energy of the maximum intensity in parentheses): Pt/P90-C (11568.3 eV) $\geq$ PtO $_{2}(11567.6 \mathrm{eV}) \geq \mathrm{Pt} / \mathrm{PC} 500-\mathrm{C}(11568.3 \mathrm{eV})>\mathrm{Pt} / \mathrm{PC} 500-\mathrm{R}$ $(11566.1 \mathrm{eV}) \geq \mathrm{Pt}(11565.1 \mathrm{eV})$. The comparison with reference $\mathrm{PtO}_{2}$ and $\mathrm{Pt}$ samples (dotted lines in the left panel of Figure 4) suggests that the formal oxidation state of Pt in pre-calcined samples is close to IV, while it is near zero for the pre-reduced sample. Upon switching to photocatalytic reaction conditions, the XANES of the pre-reduced sample is essentially unaffected, whereas for the other two samples the WL decreases in intensity and shifts to lower energy, both events revealing a reduction of Pt species. The WL intensity order is changed as the following: Pt/PC500-C (11566.6 eV) > Pt/P90-C $(11566.7 \mathrm{eV}) \approx \mathrm{Pt} / \mathrm{PC} 500-\mathrm{R}(11566.4 \mathrm{eV})$. Thus, while the Pt/P90-C catalyst appears highly sensitive to the change of environment from Dark Air to Light EtOH, the Pt/PC500-C catalyst is less sensitive, and $\mathrm{Pt} / \mathrm{PC500}-\mathrm{R}$ is almost insensitive. 

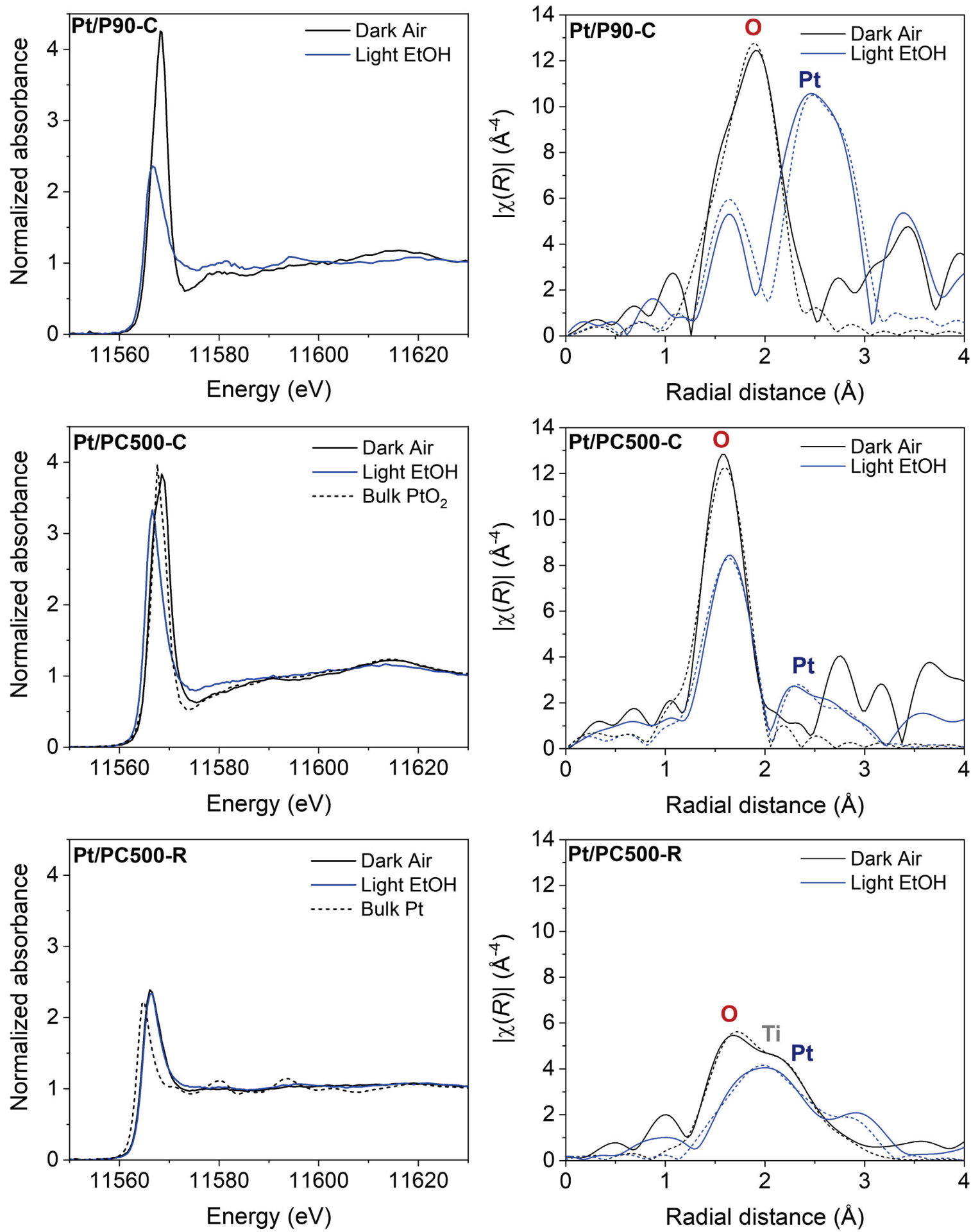

Figure 4. Left panel: $\mathrm{Pt} \mathrm{L}_{3}$-edge HERFD-XANES spectra of $0.2 \mathrm{wt} \% \mathrm{Pt} / \mathrm{TiO}_{2}$ photocatalysts in the dark under air atmosphere (Dark Air) versus under UV-Vis irradiation in ethanol/water/helium gas flow (Light EtOH). Bulk $\mathrm{PtO}_{2}$ and $\mathrm{Pt}$ reference spectra are represented with dotted lines. Right panel: corresponding $\mathrm{k}^{3}$-weighted EXAFS FT modulus. Best fits are represented with dotted lines. The radial distance is not phase-corrected. Rough positions of first-neighbor features are labeled with proper elements. 
Table 1. EXAFS fitting values.

\begin{tabular}{|c|c|c|c|c|}
\hline Scatterer & $C N$ & $R(\AA)$ & $\sigma^{2}\left(\AA^{2}\right)$ & $\Delta E_{0}(e V)$ \\
\hline \multicolumn{5}{|c|}{ Pt/P90-C DA: $v=0.14$} \\
\hline $\mathrm{O}$ & $4.4(6)$ & $2.08(4)$ & $0.0040(7)$ & $16(3)$ \\
\hline \multicolumn{5}{|c|}{ Pt/P90-C LE: $v=0.22$} \\
\hline $\mathrm{O}$ & $2.0(8)$ & $2.04(3)$ & $0.006(1)$ & $15(2)$ \\
\hline $\mathrm{Pt}$ & $7.0(8)$ & $2.75(2)$ & $0.006(1)$ & $5(3)$ \\
\hline \multicolumn{5}{|c|}{ Pt/PC500-C DA: $v=0.12$} \\
\hline $\mathrm{O}$ & $5.0(4)$ & $2.00(2)$ & $0.005(1)$ & $11(3)$ \\
\hline \multicolumn{5}{|c|}{ Pt/PC500-C LE: $v=0.13$} \\
\hline $\mathrm{O}$ & $3.0(5)$ & $2.02(2)$ & $0.005(1)$ & $12(2)$ \\
\hline Pt & $1.6(5)$ & $2.73(2)$ & $0.005(1)$ & $5(1)$ \\
\hline \multicolumn{5}{|c|}{ Pt/PC500-R DA: $v=0.17$} \\
\hline $\mathrm{O}$ & $2.1(5)$ & $2.01(3)$ & $0.005(1)$ & $12(2)$ \\
\hline $\mathrm{Pt}$ & $1.3(8)$ & $2.72(2)$ & $0.008(2)$ & $6(2)$ \\
\hline $\mathrm{Ti}$ & $1.7(5)$ & $2.53(3)$ & $0.008(1)$ & $-3(2)$ \\
\hline \multicolumn{5}{|c|}{ Pt/PC500-R LE: $v=0.18$} \\
\hline $\mathrm{O}$ & $0.9(5)$ & $2.00(2)$ & $0.005(1)$ & $11(2)$ \\
\hline $\mathrm{Pt}$ & $3.3(8)$ & $2.71(2)$ & $0.009(2)$ & $5(2)$ \\
\hline $\mathrm{Ti}$ & $1.3(5)$ & $2.51(3)$ & $0.006(2)$ & $-4(2)$ \\
\hline \multicolumn{5}{|c|}{$\mathrm{PtO}_{2}$ ref. DA: $v=0.22^{\mathrm{a}}$} \\
\hline $\mathrm{O}$ & 4 & $1.93(2)$ & $0.008(2)$ & $14(3)$ \\
\hline $\mathrm{O}$ & 2 & $2.02(3)$ & $0.007(2)$ & $15(3)$ \\
\hline $\mathrm{Pt}$ & 2 & $3.17(3)$ & $0.005(2)$ & $8(3)$ \\
\hline $\mathrm{O}$ & 2 & $3.19(3)$ & $0.009(2)$ & $12(3)$ \\
\hline Pt & 8 & $3.62(3)$ & $0.011(1)$ & $6(3)$ \\
\hline \multicolumn{5}{|c|}{ Pt ref. DA: $v=0.07^{\mathrm{a}}$} \\
\hline $\mathrm{Pt}$ & 12 & $2.76(1)$ & $0.0053(5)$ & $6.2(6)$ \\
\hline
\end{tabular}

$C N$ is the coordination number; $R$ is the radial distance between absorber and scatterer atoms; $\sigma^{2}$ is the mean square variation in path length; $\Delta E_{0}$ is the energy variance; $v$ is the goodness of the fit. The two letters after the sample name correspond to operating conditions, with first letter for Dark or Light and second letter for Air, Helium flow, or Ethanol/water/helium flow. ${ }^{a} \mathrm{CN}$ set as in the crystalline compound. The number in parentheses represents the error on the last significant digit. 
The corresponding EXAFS data (Fourier transform modulus $|\chi(R)|$ ) together with numerical fits are reported in the right panel of Figure 4 and Table 1 (additionally, Figures S14-S17 report $\operatorname{Im}[\chi(R)], k^{3} \chi(k)$, wavelet transform, and $\mathrm{Pt} / \mathrm{PtO}_{2}$ reference data). The EXAFS features agree with the trends established from HERFD-XANES analysis. For Pt/P90-C, the EXAFS Fourier transform (FT) modulus shows a switch from Pt-O coordination - corresponding to single Pt atoms coordinated to 4-5 $\mathrm{O}$ atoms - to predominant Pt-Pt coordination with 6-8 neighbors, corresponding to Pt clusters. The Pt/PC500-C sample, which initially mostly contains single atoms coordinated to $5 \mathrm{O}$ atoms, shows an only slight clustering upon exposure to photocatalytic conditions, with a Pt-Pt CN of 1-2. As suggested by the moderate decrease in WL intensity and Pt- $\mathrm{O} C N$, the reaction-induced Pt reduction is also moderate. Finally, the EXAFS of the as-prepared Pt/PC500-R sample reveals, in addition to Pt-O bonds, the presence of Pt-Ti bonds, which were not identified in the other two samples. In particular, EXAFS fitting does not support the presence of such bonds in Pt/PC500-C. It is noted that Pt-Ti coordination has been reported in the literature for $\mathrm{Pt} / \mathrm{TiO}_{2} \mathrm{SACs}$, though with larger radial distances (2.65-3.89 $\AA$ vs. 2.53-2.56 $\AA$ here) ${ }^{28,42}$ From the low contribution of the Pt-Pt scattering path in initial state ( $C N=1.3 \pm$ 0.8 ), one can infer either that the clusters observed by STEM are oxidic, or that single Pt atoms are highly predominant. The first possibility is unlikely as there is little chance that the reducing treatment leads to oxidized clusters, as corroborated by XANES. When exposed to reaction conditions, the Pt-Pt $\mathrm{CN}$ increases to ca. 3, while the sample retains some Pt-Ti coordination. The results thus suggest that a significant fraction of $\mathrm{Pt}$ in $\mathrm{Pt} / \mathrm{PC500}-\mathrm{R}$ consists of single Pt atoms coordinated to $\mathrm{O}$ and $\mathrm{Ti}$ atoms; part of the corresponding bonds is removed during the in situ experiment, together with Pt clustering to some extent. However, the partial elimination of oxygen neighbors leads only to a very slight decrease of the WL intensity in XANES, indicating that unlike the pre-calcined counterpart (Pt/PC500C), most of the platinum in as-prepared Pt/PC500-R is already in reduced state. The latter may be stabilized by $\mathrm{Pt}$ neighboring to $\mathrm{Ti}^{3+}$ sites and $\mathrm{O}$ vacancies (see next section).

To evaluate the overall restructuring processes, the samples were analyzed by STEM after the XAS experiments (bottom panel of Figure 2 and Figures S1-S9). For the Pt/P90-C sample, initially composed of single atoms/multimers and a small fraction of subnanometric clusters, the Pt species range from single atoms to nanoparticles up to ca. $2.5 \mathrm{~nm}$ in average size after the reaction. The particle type distributions in Figure S9 show that the Pt multimer/monomer ratio increases, while Pt species larger than $1 \mathrm{~nm}$ remain a minority. The structural instability of the Pt/P90-C catalyst is associated with its catalytic instability (Figure 3). For Pt/PC500-C, post-reaction STEM reveals only a slight decrease in Pt dispersion, i.e. Pt remains in the form of single atoms and few-atom clusters, though with a slight increase in the multimer/monomer ratio (Figure S9). Consistently, EXAFS shows the formation of Pt-Pt bonds with a $\mathrm{CN}$ of $1.6 \pm 0.5$, which indicates the presence of Pt dimers and trimers, whereas single 
atoms were the majority species before the reaction (no detectable Pt neighbor). Finally, for Pt/PC500$R$, post-reaction STEM still shows the presence of single atoms and similar sized-clusters $(1.4 \pm 0.3 \mathrm{~nm})$ as before the reaction, but the latter population is now more abundant (Figure S9), in agreement with the increase in average Pt-Pt coordination detected by EXAFS.

\section{Discussion}

In summary, similarly to the effect of $\mathrm{H}_{2}$ or CO on alumina-supported Pt SACs, ${ }^{65,66}$ fully oxidized Pt(IV) single atoms are easily transformed into Pt clusters on P90 titania by the effect of photocatalytic reaction conditions. In contrast, single Pt atoms are much more stabilized by PC500 titania. In this case, single Pt atoms and few-atom Pt clusters with partially retained O ligands are stable upon the reaction. Moreover, the pre-reduction of Pt/PC500 is only slightly detrimental to Pt dispersion, and this correlates with Pt-Ti bonding.

This Pt-Ti state may be related to the phenomenon well-known in heterogeneous catalysis as strong metal-support interaction (SMSI). SMSI leads to the inhibition of chemisorption and catalysis due to the presence of a reduced titanium oxide, $\mathrm{TiO}_{x}$, at the surface of Pt crystallites. ${ }^{55,67,68}$ In our case, in the initial state, there are no Pt crystallites but single atoms interacting with partially reduced $\mathrm{Ti}$ species. This is consistent with a recent report by $\mathrm{Han}$ et al. on a $\mathrm{Pt} / \mathrm{TiO}_{2} \mathrm{SAC}$ based on $\mathrm{TiO}_{2}(\mathrm{~B})$ nanosheets. ${ }^{33}$ Similar SMSI effects have been suggested from XAS and XPS in low-temperature experiments involving hydrogen evolution..$^{69,70}$

The striking difference between the two titanias in terms of Pt-Ti bond formation probably comes from their properties related to the preparation technique. $\mathrm{P90} \mathrm{TiO}_{2}$ is prepared according to the AEROXIDE ${ }^{\circledR}$ process, in which titanium tetrachloride is vaporized and then reacted in the oxyhydrogen flame, above $2000{ }^{\circ} \mathrm{C} .{ }^{71}$ This explains the high crystallinity and the low reactivity/reducibility of the P90 surface, which does not form oxygen vacancies (correlated to Pt-Ti bond formation) upon reducing treatment at $300{ }^{\circ} \mathrm{C}$. By contrast, the $\mathrm{PC500} \mathrm{TiO}_{2}$ nanopowder is synthesized through the sulfate process, consisting of multi-step wet chemistry procedures followed by final calcination. ${ }^{72}$ The high defectiveness (including $\mathrm{Ti}^{3+}$ sites and oxygen vacancies) ${ }^{60}$ of the PC500 surface, together with its high specific surface area, can explain why it is more prone than P90 to show SMSI-related effects at temperatures as low as $300^{\circ} \mathrm{C}$.

The Pt-O coordination numbers (CNs) in our as-prepared pre-calcined catalysts lie in the 4-5 range (Table 1), in agreement with the $\mathrm{Pt} / \mathrm{TiO}_{2}$ SACs reported in the literature. ${ }^{28-30,34,36,47}$ The EXAFS information being inherently averaged over the sample, the co-existence of single Pt atoms with a fraction of Pt clusters in the Pt/P90-C sample most likely explains the slightly lower value of the Pt-O 
CN (4.4 \pm 0.6$)$ with respect to the Pt/P500-C SAC (5.0 \pm 0.4$)$. In these calcined samples, Pt substitution for Ti cannot be ruled out, ${ }^{28}$ but the Pt-O CN lower than 6 rather suggests mostly Pt adsorption at $\mathrm{TiO}_{2}$ terraces or step edges. It could be argued that small $\mathrm{PtO}_{\mathrm{x}}$ clusters may coexist with single $\mathrm{Pt}$ atoms replacing $\mathrm{Ti}$ in the titania lattice, which would result in a decrease of the average Pt-O CN. However, neither STEM nor EXAFS confirm this hypothesis. In particular, the wavelet transform analysis of Figure S16 suggests that no clear heavy neighbor is present around Pt, i.e. the existence of a well-defined PtO-Pt scattering path is unlikely. Indeed, in the wavelet maps for the calcined samples the intensity spots corresponding to $R$ values of 2.5-4.0 $\AA$ are smeared over the whole $k$ scale instead of being localized around 7-8 $\AA^{-1}$, as it should be for well-defined Pt scatterers (e.g. in Pt oxide clusters). Therefore, this intensity corresponds rather to $\mathrm{Pt}-\mathrm{O}$ wiggles, or to $\mathrm{Ti}$ in $\mathrm{Pt}-\mathrm{O}-\mathrm{Ti}$ moieties, though the presence of some Pt cannot be excluded as well.

In the work of $\mathrm{Li}$ et al. on nanoparticulate $\mathrm{PtO} / \mathrm{TiO}_{2}$ photocatalysts under photocatalytic liquid water splitting conditions, ${ }^{56}$ a decrease in Pt-O CN from 4.0 to 2.5 was reported, consistently with our measurements on pre-calcined catalysts. However, the authors did not observe any Pt-Pt coordination and measured an increase in Pt-O bond length from $2.07 \AA$ to $2.13 \AA$ under operating conditions. The fact that we did not measure such an elongation suggests that the active Pt species identified in our work differ from the supported Pt oxides investigated by Li et al.

As a switch to UV-Vis light irradiation from dark dry conditions has no significant effect on the oxidation state of Pt (Figure S12), the reduction and clustering of Pt species can be associated with ethanol/water adsorption, hydrogen evolution or/and the photocatalytic reaction itself. Moreover, the reduction process is irreversible upon switching from Light EtOH to Dark EtOH conditions (Figure S12). In their operando water splitting study on $\mathrm{PtO} / \mathrm{TiO}_{2}$ photocatalysts, Li et al. observed only a slight reducing effect of liquid water adsorption in the absence of light. ${ }^{56}$ Using angle-resolved $X$-ray photoelectron spectroscopy (XPS) to investigate nanoparticulate $\mathrm{Pt} /$ rutile- $\mathrm{TiO}_{2}$ photocatalysts submitted to water adsorption, Zhang et al. observed a reversible full reduction of PtO species upon UV light irradiation. ${ }^{70}$ Similarly, Lee et al. revealed a photoactivation of $\mathrm{Cu} / \mathrm{TiO}_{2}$ SACs for PHER from a water/methanol solution under UV light irradiation. ${ }^{39}$ The overall process consists in $\mathrm{Cu}^{2+}$ to $\mathrm{Cu}^{+}$reduction and simultaneous local distortion of the $\mathrm{TiO}_{2}$ lattice. Put together, these data suggest that the Pt reduction we observe under PHER conditions is induced by the trapping of photogenerated electrons. However, in our case, the clustering of Pt atoms together with ethanol/water adsorption may kinetically prevent Pt re-oxidation upon light extinction, explaining the irreversibility observed in XAS (Figure S12).

The main difference between the PHER performances of the three catalysts lies in their stabilities, with $\mathrm{Pt} / \mathrm{P90}-\mathrm{C}$ being the least stable catalyst and Pt/PC500-R the most stable one. These distinct catalytic 
behaviors can be ascribed to differences in the structural stability of the supported Pt phase under reaction conditions. Even more than the $\mathrm{TiO}_{2}$ nature, the state of $\mathrm{Pt}$ (dispersion and oxidation state) was previously shown to be of first-order importance in PHER. ${ }^{50}$ In other words, the titania support plays not only a direct role from its light-absorption properties, but also an indirect one through the stabilization of the Pt phase. Namely, having more surface area - lowering the Pt-Pt clustering probability - and being more defective and reducible at its surface - enhancing Pt-titania adhesion PC500 stabilizes Pt in an isolated state much more efficiently than P90 does.

Finally, it has to be noticed that the results reported here, both from operando XAS and from STEM (pre- and post-XAS), only concern near steady-state effects, i.e. the Pt phase restructuring kinetics was not addressed. As far as the Pt/P90-C catalyst is concerned, it is possible that a large extent of the restructuring in photocatalytic reaction conditions occurs at the very beginning (first minutes) of the light-ethanol/water mixture exposure. Then, slower restructuring would occur, leading to the measured change in PHER reaction rate. For Pt/PC500-C, though we also cannot exclude an initial fast restructuring, the continuous and moderate increase in activity may be ascribed to Pt dimer and possibly trimer formation. Operando analysis of SAC restructuring kinetics through fast XAS methods is an important target of research. .5, $66^{-6}$

\section{Conclusions}

The behavior of ultradispersed cationic Pt catalysts supported on commercial titania during photocatalytic HER from a gas-phase ethanol-water mixture under UV-Vis irradiation was investigated by operando XAS at the Pt- $\mathrm{L}_{3}$ edge. In complement, high-resolution STEM was performed before and after these experiments, and laboratory photocatalytic tests were conducted.

Under photocatalytic XAS conditions on pre-calcined SACs, the general trend with respect to initial conditions is a decrease in Pt-O coordination ( $\mathrm{CN}$ from 4-5 to 2-3), i.e. a partial reduction of Pt species. In addition, the SACs show partial Pt-Pt clustering under reaction conditions. While the clustering extent is high for anatase-rich $\mathrm{P90}$ titania (Pt-Pt CN of 7), this process can be significantly restrained by using a titania support with high specific surface area and high surface defectiveness. This is demonstrated for the pre-calcined Pt/PC500 anatase-rich system, which retains a high Pt oxidation state and an atomic Pt dispersion composed of single atoms, dimers, and trimers (Pt-Pt CN of 1-2) during the photocatalytic reaction.

Finally, XAS reveals the limited reaction-induced evolution of the pre-reduced Pt/PC500 system, which exhibits single atoms and small Pt clusters with Pt-O and Pt-Ti bonds. HERFD-XANES shows that Pt is quasi neutral, both before and during the reaction. This catalyst is more active and stable than its pre- 
calcined and even-more-dispersed counterpart. Thus, photocatalyst preparation by Pt impregnation on a high-surface-area anatase support followed by a mild reducing treatment appears as a simple and optimal strategy in terms of electronic and catalytic stability, while maximizing the PHER efficiency.

\section{Supporting Information}

Experimental details, STEM images and related analyses, catalytic data, XAS data and related analyses. This information is available free of charge on the ACS Publications website

\section{Acknowledgements}

Région Auvergne-Rhône-Alpes (CMIRA 2016 project) and Agence Nationale de la Recherche (UltraCat project ANR-17-CE06-0008 and LABEX IMUST ANR-10-LABX-0064/ANR-11-IDEX-0007) are acknowledged for financial support.

ESRF is acknowledged for XAS run \#20171370.

The FAME-UHD project is financially supported by the French "grand emprunt" EquipEx (EcoX, ANR10-EQPX-27-01), the CEA-CNRS CRG consortium and the INSU CNRS institute. The ROBL-BM20 beamline is acknowledged for the loan of crystal analyzer.

CLYM is acknowledged for access to the Titan microscope.

JL is a Serra Húnter fellow and is grateful to ICREA Academia program and projects MICINN/FEDER RTI2018-093996-B-C31 and GC 2017 SGR 128. LS is grateful to project MICINN/FEDER RTI2018-095498$\mathrm{J}-100$

\section{References}

(1) Nguyen, T.-S.; Postole, G.; Loridant, S.; Bosselet, F.; Burel, L.; Aouine, M.; Massin, L.; Morfin, F.; Gélin, P.; Piccolo, L. Ultrastable Iridium-Ceria Nanopowders Synthesized in One Step by Solution Combustion for Catalytic Hydrogen Production. J. Mater. Chem. A 2014, 2, 19822-19832. https://doi.org/10.1039/c4ta04820b.

(2) Fujishima, A.; Honda, K. Electrochemical Photolysis of Water at a Semiconductor Electrode. Nature 1972, 238 (5358), 37-38. https://doi.org/10.1038/238037a0.

(3) Ahmad, H.; Kamarudin, S. K.; Minggu, L. J.; Kassim, M. Hydrogen from Photo-Catalytic Water Splitting Process: A Review. Renewable Sustainable Energy Rev. 2015, 43, 599-610. https://doi.org/10.1016/j.rser.2014.10.101. 
(4) Montoya, J. H.; Seitz, L. C.; Chakthranont, P.; Vojvodic, A.; Jaramillo, T. F.; Nørskov, J. K. Materials for Solar Fuels and Chemicals. Nat. Mater. 2017, 16 (1), 70-81.

https://doi.org/10.1038/nmat4778.

(5) Takanabe, K. Photocatalytic Water Splitting: Quantitative Approaches toward Photocatalyst by Design. ACS Catal. 2017, 7 (11), 8006-8022. https://doi.org/10.1021/acscatal.7b02662.

(6) Wang, Z.; Li, C.; Domen, K. Recent Developments in Heterogeneous Photocatalysts for SolarDriven Overall Water Splitting. Chem. Soc. Rev. 2019, 48 (7), 2109-2125. https://doi.org/10.1039/C8CS00542G.

(7) Yang, Y. Z.; Chang, C.-H.; Idriss, H. Photo-Catalytic Production of Hydrogen from Ethanol over $\mathrm{M} / \mathrm{TiO}_{2}$ Catalysts (M=Pd, Pt or Rh). Appl. Catal. B 2006, 67 (3), 217-222. https://doi.org/10.1016/j.apcatb.2006.05.007.

(8) Al-Azri, Z. H. N.; Chen, W.-T.; Chan, A.; Jovic, V.; Ina, T.; Idriss, H.; Waterhouse, G. I. N. The Roles of Metal Co-Catalysts and Reaction Media in Photocatalytic Hydrogen Production: Performance Evaluation of $\mathrm{M} / \mathrm{TiO}_{2}$ Photocatalysts ( $\mathrm{M}=\mathrm{Pd}, \mathrm{Pt}, \mathrm{Au}$ ) in Different Alcohol-Water Mixtures. J. Catal. 2015, 329, 355-367. https://doi.org/10.1016/j.jcat.2015.06.005.

(9) Kumaravel, V.; Imam, M. D.; Badreldin, A.; Chava, R. K.; Do, J. Y.; Kang, M.; Abdel-Wahab, A. Photocatalytic Hydrogen Production: Role of Sacrificial Reagents on the Activity of Oxide, Carbon, and Sulfide Catalysts. Catalysts 2019, 9 (3), 276. https://doi.org/10.3390/catal9030276.

(10) Denisov, N.; Yoo, J.; Schmuki, P. Effect of Different Hole Scavengers on the Photoelectrochemical Properties and Photocatalytic Hydrogen Evolution Performance of Pristine and Pt-Decorated $\mathrm{TiO}_{2}$ Nanotubes. Electrochim. Acta 2019, 319, 61-71. https://doi.org/10.1016/j.electacta.2019.06.173.

(11) Kondarides, D. I.; Daskalaki, V. M.; Patsoura, A.; Verykios, X. E. Hydrogen Production by PhotoInduced Reforming of Biomass Components and Derivatives at Ambient Conditions. Catal. Lett. 2008, 122 (1-2), 26-32. https://doi.org/10.1007/s10562-007-9330-3.

(12) Bowker, M.; Morton, C.; Kennedy, J.; Bahruji, H.; Greves, J.; Jones, W.; Davies, P. R.; Brookes, C.; Wells, P. P.; Dimitratos, N. Hydrogen Production by Photoreforming of Biofuels Using Au, Pd and $\mathrm{Au}-\mathrm{Pd} / \mathrm{TiO}_{2}$ Photocatalysts. J. Catal. 2014, 310, 10-15. https://doi.org/10.1016/j.jcat.2013.04.005.

(13) Puga, A. V. Photocatalytic Production of Hydrogen from Biomass-Derived Feedstocks. Coord. Chem. Rev. 2016, 315, 1-66. https://doi.org/10.1016/j.ccr.2015.12.009.

(14) Kennedy, J.; Bahruji, H.; Bowker, M.; Davies, P. R.; Bouleghlimat, E.; Issarapanacheewin, S. Hydrogen Generation by Photocatalytic Reforming of Potential Biofuels: Polyols, Cyclic Alcohols, and Saccharides. J. Photochem. Photobiol. A 2018, 356, 451-456. https://doi.org/10.1016/j.jphotochem.2018.01.031.

(15) Kumaravel, V.; Mathew, S.; Bartlett, J.; Pillai, S. C. Photocatalytic Hydrogen Production Using Metal Doped TiO 2 : A Review of Recent Advances. Appl. Catal. B 2019, 244, 1021-1064. https://doi.org/10.1016/j.apcatb.2018.11.080.

(16) Murdoch, M.; Waterhouse, G. I. N.; Nadeem, M. A.; Metson, J. B.; Keane, M. A.; Howe, R. F.; Llorca, J.; Idriss, H. The Effect of Gold Loading and Particle Size on Photocatalytic Hydrogen Production from Ethanol over $\mathrm{Au} / \mathrm{TiO}_{2}$ Nanoparticles. Nat. Chem. 2011, 3 (6), 489-492. https://doi.org/10.1038/nchem.1048.

(17) Yang, J.; Wang, D.; Han, H.; Li, C. Roles of Cocatalysts in Photocatalysis and Photoelectrocatalysis. Acc. Chem. Res. 2013, 46 (8), 1900-1909. https://doi.org/10.1021/ar300227e.

(18) Low, J.; Yu, J.; Jaroniec, M.; Wageh, S.; Al-Ghamdi, A. A. Heterojunction Photocatalysts. Adv. Mater. 2017, 29 (20), 1601694. https://doi.org/10.1002/adma.201601694.

(19) Chen, Y.; Feng, X.; Guo, X.; Zheng, W. Toward a Fundamental Understanding of Factors Affecting the Function of Cocatalysts in Photocatalytic Water Splitting. Current Opinion in Green and Sustainable Chemistry 2019, 17, 21-28. https://doi.org/10.1016/j.cogsc.2019.01.002. 
(20) Yu, J.; Qi, L.; Jaroniec, M. Hydrogen Production by Photocatalytic Water Splitting over Pt/TiO Nanosheets with Exposed (001) Facets. J. Phys. Chem. C 2010, 114 (30), 13118-13125. https://doi.org/10.1021/jp104488b.

(21) Kandiel, T. A.; Dillert, R.; Robben, L.; Bahnemann, D. W. Photonic Efficiency and Mechanism of Photocatalytic Molecular Hydrogen Production over Platinized Titanium Dioxide from Aqueous Methanol Solutions. Catal. Today 2011, 161 (1), 196-201. https://doi.org/10.1016/j.cattod.2010.08.012.

(22) Navarro, R. M.; Arenales, J.; Vaquero, F.; González, I. D.; Fierro, J. L. G. The Effect of Pt Characteristics on the Photoactivity of $\mathrm{Pt} / \mathrm{TiO}_{2}$ for Hydrogen Production from Ethanol. Catal. Today 2013, 210, 33-38. https://doi.org/10.1016/j.cattod.2013.01.006.

(23) Li, H.; Yu, H.; Sun, L.; Zhai, J.; Han, X. A Self-Assembled 3D Pt/TiO 2 Architecture for HighPerformance Photocatalytic Hydrogen Production. Nanoscale 2015, 7 (5), 1610-1615. https://doi.org/10.1039/C4NR06310D.

(24) Wang, A.; Li, J.; Zhang, T. Heterogeneous Single-Atom Catalysis. Nat. Rev. Chem. 2018, 2 (6), 65-81. https://doi.org/10.1038/s41570-018-0010-1.

(25) Yang, M.; Liu, J.; Lee, S.; Zugic, B.; Huang, J.; Allard, L. F.; Flytzani-Stephanopoulos, M. A Common Single-Site Pt(II)-O(OH $)_{x}$ - Species Stabilized by Sodium on "Active" and "Inert" Supports Catalyzes the Water-Gas Shift Reaction. J. Am. Chem. Soc. 2015, 137 (10), 3470-3473. https://doi.org/10.1021/ja513292k.

(26) DeRita, L.; Dai, S.; Lopez-Zepeda, K.; Pham, N.; Graham, G. W.; Pan, X.; Christopher, P. Catalyst Architecture for Stable Single Atom Dispersion Enables Site-Specific Spectroscopic and Reactivity Measurements of CO Adsorbed to Pt Atoms, Oxidized Pt Clusters, and Metallic Pt Clusters on $\mathrm{TiO}_{2}$. J. Am. Chem. Soc. 2017, 139 (40), 14150-14165. https://doi.org/10.1021/jacs.7b07093.

(27) Thang, H. V.; Pacchioni, G.; DeRita, L.; Christopher, P. Nature of Stable Single Atom Pt Catalysts Dispersed on Anatase $\mathrm{TiO}_{2}$. J. Catal. 2018, 367, 104-114. https://doi.org/10.1016/j.jcat.2018.08.025.

(28) DeRita, L.; Resasco, J.; Dai, S.; Boubnov, A.; Thang, H. V.; Hoffman, A. S.; Ro, I.; Graham, G. W.; Bare, S. R.; Pacchioni, G.; Pan, X.; Christopher, P. Structural Evolution of Atomically Dispersed Pt Catalysts Dictates Reactivity. Nat. Mater. 2019, 18 (7), 746. https://doi.org/10.1038/s41563019-0349-9.

(29) Wei, H.; Huang, K.; Wang, D.; Zhang, R.; Ge, B.; Ma, J.; Wen, B.; Zhang, S.; Li, Q.; Lei, M.; Zhang, C.; Irawan, J.; Liu, L.-M.; Wu, H. Iced Photochemical Reduction to Synthesize Atomically Dispersed Metals by Suppressing Nanocrystal Growth. Nat. Commun. 2017, 8 (1), 1490. https://doi.org/10.1038/s41467-017-01521-4.

(30) Chen, Y.; Ji, S.; Sun, W.; Chen, W.; Dong, J.; Wen, J.; Zhang, J.; Li, Z.; Zheng, L.; Chen, C.; Peng, Q.; Wang, D.; Li, Y. Discovering Partially Charged Single-Atom Pt for Enhanced Anti-Markovnikov Alkene Hydrosilylation. J. Am. Chem. Soc. 2018, 140 (24), 7407-7410. https://doi.org/10.1021/jacs.8b03121.

(31) Zhang, Z.; Wu, Q.; Johnson, G.; Ye, Y.; Li, X.; Li, N.; Cui, M.; Lee, J. D.; Liu, C.; Zhao, S.; Li, S.; Orlov, A.; Murray, C. B.; Zhang, X.; Gunnoe, T. B.; Su, D.; Zhang, S. Generalized Synthetic Strategy for Transition-Metal-Doped Brookite-Phase $\mathrm{TiO}_{2}$ Nanorods. J. Am. Chem. Soc. 2019, 141 (42), 16548-16552. https://doi.org/10.1021/jacs.9b06389.

(32) Fu, J.; Lym, J.; Zheng, W.; Alexopoulos, K.; Mironenko, A. V.; Li, N.; Boscoboinik, J. A.; Su, D.; Weber, R. T.; Vlachos, D. G. C-O Bond Activation Using Ultralow Loading of Noble Metal Catalysts on Moderately Reducible Oxides. Nat. Catal. 2020, 1-8. https://doi.org/10.1038/s41929-020-0445-x.

(33) Han, B.; Guo, Y.; Huang, Y.; Xi, W.; Xu, J.; Luo, J.; Qi, H.; Ren, Y.; Liu, X.; Qiao, B.; Zhang, T. Strong Metal-Support Interactions between Pt Single Atoms and $\mathrm{TiO}_{2}$. Angew. Chem. Int. Ed. 2020, 132 (29), 11922-11927. https://doi.org/10.1002/ange.202003208.

(34) Hoang, S.; Guo, Y.; Binder, A. J.; Tang, W.; Wang, S.; Liu, J. (Jimmy); Tran, H.; Lu, X.; Wang, Y.; Ding, Y.; Kyriakidou, E. A.; Yang, J.; Toops, T. J.; Pauly, T. R.; Ramprasad, R.; Gao, P.-X. Activating 
Low-Temperature Diesel Oxidation by Single-Atom Pt on $\mathrm{TiO}_{2}$ Nanowire Array. Nat. Commun. 2020, 11 (1), 1062. https://doi.org/10.1038/s41467-020-14816-w.

(35) Xu, T.; Zheng, H.; Zhang, P. Isolated Pt Single Atomic Sites Anchored on Nanoporous $\mathrm{TiO}_{2}$ Film for Highly Efficient Photocatalytic Degradation of Low Concentration Toluene. J. Hazard. Mater. 2020, 388, 121746. https://doi.org/10.1016/j.jhazmat.2019.121746.

(36) Lu, F.; Yi, D.; Liu, S.; Zhan, F.; Zhou, B.; Gu, L.; Golberg, D.; Wang, X.; Yao, J. Engineering Platinum-Oxygen Dual Catalytic Sites via Charge Transfer towards High-Efficient Hydrogen Evolution. Angew. Chem. Int. Ed. 2020, 132 (40), 17865-17871. https://doi.org/10.1002/ange.202008117.

(37) Wang, Q.; Zhang, D.; Chen, Y.; Fu, W.-F.; Lv, X.-J. Single-Atom Catalysts for Photocatalytic Reactions. ACS Sustainable Chem. Eng. 2019, 7 (7), 6430-6443. https://doi.org/10.1021/acssuschemeng.8b06273.

(38) Wang, B.; Cai, H.; Shen, S. Single Metal Atom Photocatalysis. Small Methods 2019, 3 (9), 1800447. https://doi.org/10.1002/smtd.201800447.

(39) Lee, B.-H.; Park, S.; Kim, M.; Sinha, A. K.; Lee, S. C.; Jung, E.; Chang, W. J.; Lee, K.-S.; Kim, J. H.; Cho, S.-P.; Kim, H.; Nam, K. T.; Hyeon, T. Reversible and Cooperative Photoactivation of SingleAtom Cu/TiO 2 Photocatalysts. Nat. Mater. 2019, 18 (6), 620-626. https://doi.org/10.1038/s41563-019-0344-1.

(40) Gao, C.; Low, J.; Long, R.; Kong, T.; Zhu, J.; Xiong, Y. Heterogeneous Single-Atom Photocatalysts: Fundamentals and Applications. Chem. Rev. 2020, in press. https://doi.org/10.1021/acs.chemrev.9b00840.

(41) Zhang, Q.; Guan, J. Recent Progress in Single-Atom Catalysts for Photocatalytic Water Splitting. Sol. RRL 2020, 2000283. https://doi.org/10.1002/solr.202000283.

(42) Xing, J.; Chen, J. F.; Li, Y. H.; Yuan, W. T.; Zhou, Y.; Zheng, L. R.; Wang, H. F.; Hu, P.; Wang, Y.; Zhao, H. J.; Wang, Y.; Yang, H. G. Stable Isolated Metal Atoms as Active Sites for Photocatalytic Hydrogen Evolution. Chem. Eur. J. 2014, 20 (8), 2138-2144. https://doi.org/10.1002/chem.201303366.

(43) Xing, J.; Jiang, H. B.; Chen, J. F.; Li, Y. H.; Wu, L.; Yang, S.; Zheng, L. R.; Wang, H. F.; Hu, P.; Zhao, H. J.; Yang, H. G. Active Sites on Hydrogen Evolution Photocatalyst. J. Mater. Chem. A 2013, 1 (48), 15258-15264. https://doi.org/10.1039/C3TA13167J.

(44) Li, Y. H.; Xing, J.; Yang, X. H.; Yang, H. G. Cluster Size Effects of Platinum Oxide as Active Sites in Hydrogen Evolution Reactions. Chem. Eur. J. 2014, 20 (39), 12377-12380. https://doi.org/10.1002/chem.201402989.

(45) Hang Li, Y.; Xing, J.; Jia Chen, Z.; Li, Z.; Tian, F.; Rong Zheng, L.; Feng Wang, H.; Hu, P.; Jun Zhao, H.; Gui Yang, H. Unidirectional Suppression of Hydrogen Oxidation on Oxidized Platinum Clusters. Nat. Commun. 2013, 4 (1), 2500. https://doi.org/10.1038/ncomms3500.

(46) Sui, Y.; Liu, S.; Li, T.; Liu, Q.; Jiang, T.; Guo, Y.; Luo, J.-L. Atomically Dispersed Pt on Specific $\mathrm{TiO}_{2}$ Facets for Photocatalytic $\mathrm{H}_{2}$ Evolution. J. Catal. 2017, 353, 250-255. https://doi.org/10.1016/j.jcat.2017.07.024.

(47) Chen, Y.; Ji, S.; Sun, W.; Lei, Y.; Wang, Q.; Li, A.; Chen, W.; Zhou, G.; Zhang, Z.; Wang, Y.; Zheng, L.; Zhang, Q.; Gu, L.; Han, X.; Wang, D.; Li, Y. Engineering the Atomic Interface with Single Platinum Atoms for Enhanced Photocatalytic Hydrogen Production. Angew. Chem. Int. Ed. 2020, 59 (3), 1295-1301. https://doi.org/10.1002/anie.201912439.

(48) Hejazi, S.; Mohajernia, S.; Osuagwu, B.; Zoppellaro, G.; Andryskova, P.; Tomanec, O.; Kment, S.; Zbořil, R.; Schmuki, P. On the Controlled Loading of Single Platinum Atoms as a Co-Catalyst on $\mathrm{TiO}_{2}$ Anatase for Optimized Photocatalytic $\mathrm{H}_{2}$ Generation. Adv. Mater. 2020, 32 (16), 1908505. https://doi.org/10.1002/adma.201908505.

(49) Jiang, Z.; Isaacs, M. A.; Huang, Z. W.; Shangguan, W.; Deng, Y.; Lee, A. F. Active Site Elucidation and Optimization in Pt Co-Catalysts for Photocatalytic Hydrogen Production over Titania. ChemCatChem 2017, 9 (22), 4268-4274. https://doi.org/10.1002/cctc.201700901.

(50) Dessal, C.; Martínez, L.; Maheu, C.; Len, T.; Morfin, F.; Rousset, J.-L.; Puzenat, E.; Afanasiev, P.; Aouine, M.; Soler, L.; Llorca, J.; Piccolo, L. Influence of Pt Particle Size and Reaction Phase on the 
Photocatalytic Performances of Ultradispersed $\mathrm{Pt} / \mathrm{TiO}_{2}$ Catalysts for Hydrogen Evolution. J. Catal. 2019, 375, 155-163. https://doi.org/10.1016/j.jcat.2019.05.033.

(51) Wang, D.; Liu, Z.-P.; Yang, W.-M. Revealing the Size Effect of Platinum Cocatalyst for Photocatalytic Hydrogen Evolution on $\mathrm{TiO}_{2}$ Support: A DFT Study. ACS Catal. 2018, 8 (8), 72707278. https://doi.org/10.1021/acscatal.8b01886.

(52) Schweinberger, F. F.; Berr, M. J.; Döblinger, M.; Wolff, C.; Sanwald, K. E.; Crampton, A. S.; Ridge, C. J.; Jäckel, F.; Feldmann, J.; Tschurl, M.; Heiz, U. Cluster Size Effects in the Photocatalytic Hydrogen Evolution Reaction. J. Am. Chem. Soc. 2013, 135 (36), 13262-13265. https://doi.org/10.1021/ja406070q.

(53) Liu, L.; Meira, D. M.; Arenal, R.; Concepcion, P.; Puga, A. V.; Corma, A. Determination of the Evolution of Heterogeneous Single Metal Atoms and Nanoclusters under Reaction Conditions: Which Are the Working Catalytic Sites? ACS Catal. 2019, 9, 10626-10639. https://doi.org/10.1021/acscatal.9b04214.

(54) Jeantelot, G.; Qureshi, M.; Harb, M.; Ould-Chikh, S.; Anjum, D. H.; Abou-Hamad, E.; AguilarTapia, A.; Hazemann, J.-L.; Takanabe, K.; Basset, J.-M. TiO ${ }_{2}$-Supported Pt Single Atoms by Surface Organometallic Chemistry for Photocatalytic Hydrogen Evolution. Phys. Chem. Chem. Phys. 2019, 21 (44), 24429-24440. https://doi.org/10.1039/C9CP04470A.

(55) Piccolo, L. Restructuring Effects of the Chemical Environment in Metal Nanocatalysis and SingleAtom Catalysis. Catal. Today in press. https://doi.org/10.1016/j.cattod.2020.03.052.

(56) Li, Y. H.; Li, C.; Yang, H. G. Quantitative Analysis of the PtO Structure during Photocatalytic Water Splitting by Operando XAFS. J. Mater. Chem. A 2017, 5 (39), 20631-20634. https://doi.org/10.1039/C7TA07440A.

(57) Muñoz-Batista, M. J.; Motta Meira, D.; Colón, G.; Kubacka, A.; Fernández-García, M. PhaseContact Engineering in Mono- and Bimetallic Cu-Ni Co-Catalysts for Hydrogen Photocatalytic Materials. Angew. Chem. Int. Ed. 2018, 57 (5), 1199-1203. https://doi.org/10.1002/anie.201709552.

(58) Caudillo-Flores, U.; Barba-Nieto, I.; Muñoz-Batista, M. J.; Kubacka, A.; Fernández-García, M. Characterization of Photo-Catalysts: From Traditional to Advanced Approaches. Top. Curr. Chem. 2019, 377 (5), 24. https://doi.org/10.1007/s41061-019-0248-1.

(59) Zhou, Y.; Doronkin, D. E.; Zhao, Z.; Plessow, P. N.; Jelic, J.; Detlefs, B.; Pruessmann, T.; Studt, F.; Grunwaldt, J.-D. Photothermal Catalysis over Nonplasmonic $\mathrm{Pt} / \mathrm{TiO}_{2}$ Studied by Operando HERFD-XANES, Resonant XES, and DRIFTS. ACS Catal. 2018, 8 (12), 11398-11406. https://doi.org/10.1021/acscatal.8b03724.

(60) Keulemans, M.; Verbruggen, S. W.; Hauchecorne, B.; Martens, J. A.; Lenaerts, S. Activity versus Selectivity in Photocatalysis: Morphological or Electronic Properties Tipping the Scale. J. Catal. 2016, 344, 221-228. https://doi.org/10.1016/j.jcat.2016.09.033.

(61) Molins, E.; Benito, M.; Mata, I.; Martínez, L.; Soler, L.; Llorca, J. Au/ $\mathrm{TiO}_{2}$ Lyogels for Hydrogen Production. MRS Adv. 2017, 2 (57), 3499-3504. https://doi.org/10.1557/adv.2017.346.

(62) Martínez, L.; Benito, M.; Mata, I.; Soler, L.; Molins, E.; Llorca, J. Preparation and Photocatalytic Activity of $\mathrm{Au} / \mathrm{TiO}_{2}$ Lyogels for Hydrogen Production. Sustainable Energy Fuels 2018, 2 (10), 2284-2295. https://doi.org/10.1039/C8SE00293B.

(63) Dai, Y.; Gorey, T. J.; Anderson, S. L.; Lee, S.; Lee, S.; Seifert, S.; Winans, R. E. Inherent Size Effects on XANES of Nanometer Metal Clusters: Size-Selected Platinum Clusters on Silica. J. Phys. Chem. C 2017, 121 (1), 361-374. https://doi.org/10.1021/acs.jpcc.6b10167.

(64) Timoshenko, J.; Lu, D.; Lin, Y.; Frenkel, A. I. Supervised Machine-Learning-Based Determination of Three-Dimensional Structure of Metallic Nanoparticles. J. Phys. Chem. Lett. 2017, 8 (20), 5091-5098. https://doi.org/10.1021/acs.jpclett.7b02364.

(65) Dessal, C.; Sangnier, A.; Chizallet, C.; Dujardin, C.; Morfin, F.; Rousset, J.-L.; Aouine, M.; Bugnet, M.; Afanasiev, P.; Piccolo, L. Atmosphere-Dependent Stability and Mobility of Catalytic Pt Single Atoms and Clusters on $\mathrm{\gamma}-\mathrm{Al}_{2} \mathrm{O}_{3}$. Nanoscale 2019, 11 (14), 6897-6904. https://doi.org/10.1039/C9NR01641D. 
(66) Dessal, C.; Len, T.; Morfin, F.; Rousset, J.-L.; Aouine, M.; Afanasiev, P.; Piccolo, L. Dynamics of Single Pt Atoms on Alumina during CO Oxidation Monitored by Operando X-Ray and Infrared Spectroscopies. ACS Catal. 2019, 9, 5752-5759. https://doi.org/10.1021/acscatal.9b00903.

(67) Spencer, M. S. Models of Strong Metal-Support Interaction (SMSI) in Pt on $\mathrm{TiO}_{2}$ Catalysts. J. Catal. 1985, 93 (2), 216-223. https://doi.org/10.1016/0021-9517(85)90169-1.

(68) Tauster, S. J. Strong Metal-Support Interactions. Acc. Chem. Res. 1987, 20 (11), 389-394. https://doi.org/10.1021/ar00143a001.

(69) Cheng, X.; Li, Y.; Zheng, L.; Yan, Y.; Zhang, Y.; Chen, G.; Sun, S.; Zhang, J. Highly Active, Stable Oxidized Platinum Clusters as Electrocatalysts for the Hydrogen Evolution Reaction. Energy Environ. Sci. 2017, 10 (11), 2450-2458. https://doi.org/10.1039/C7EE02537H.

(70) Zhang, Y.; Hu, H.; Huang, X.; Bi, Y. Photo-Controlled Bond Changes on $\mathrm{Pt} / \mathrm{TiO}{ }_{2}$ for Promoting Overall Water Splitting and Restraining Hydrogen-Oxygen Recombination. J. Mater. Chem. A 2019, 7 (11), 5938-5942. https://doi.org/10.1039/C8TA11595H.

(71) Technical Overview 13: AEROXIDE ${ }^{\circledR}$ - Fumed Metal Oxides. https://www.aerosil.com/product/aerosil/downloads/to-aeroxide-en.pdf.

(72) Ginsberg, T.; Modigell, M.; Wilsmann, W. Thermochemical Characterisation of the Calcination Process Step in the Sulphate Method for Production of Titanium Dioxide. Chem. Eng. Res. Des. 2011, 89 (7), 990-994. https://doi.org/10.1016/j.cherd.2010.11.006. 